\title{
Differential membrane type 1 matrix metalloproteinase substrate processing with ischemia-reperfusion: Relationship to interstitial microRNA dynamics and myocardial function
}

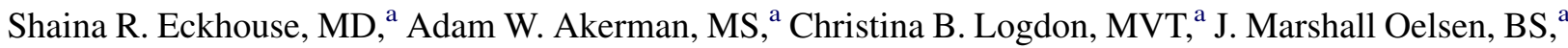
Elizabeth C. O'Quinn, BS, ${ }^{\text {a }}$ Elizabeth K. Nadeau, BS, ${ }^{\mathrm{a}}$ Robert E. Stroud, MS, ${ }^{\mathrm{a}}$ Rupak Mukherjee, PhD, ${ }^{\mathrm{a}}$ Jeffrey A. Jones, $\mathrm{PhD},{ }^{\mathrm{a}}$ and Francis $\mathrm{G}$. Spinale, $\mathrm{MD}, \mathrm{PhD}^{\mathrm{a}, \mathrm{b}}$

Objectives: Membrane type 1 matrix metalloproteinase (MT1-MMP) is critical to a number of proteolytic and profibrotic events. However, upstream regulation of MT1-MMP with myocardial ischemia-reperfusion remains poorly understood. MicroRNAs regulate post-transcriptional events, and in silico mapping has identified a conserved sequence in MT1-MMP for microRNA-133a. This study tested the hypothesis that changes in microRNA-133a regulation occur with myocardial ischemia-reperfusion, which contributes to time- and region-dependent changes in MT1-MMP activity and processing of MT1-MMP substrates.

Methods: Yorkshire pigs $(\mathrm{n}=12)$ underwent ischemia-reperfusion (90 minutes ischemia and 120 minutes reperfusion), where regional preload recruitable stroke work (sonomicrometry), interstitial MT1-MMP activity (microdialysis), Smad2 abundance (immunoblotting), and interstitial microRNA-133a (polymerase chain reaction) were determined within the ischemia-reperfusion and remote regions. Human left ventricular fibroblasts were transduced with microRNA-133a and anti-microRNA-133a (lentivirus) to determine the effects on MT1-MMP protein abundance.

Results: With ischemia-reperfusion, regional preload recruitable stroke work decreased from steady state $(139 \pm 20 \mathrm{~mm} \mathrm{Hg}$ to $44 \pm 11 \mathrm{~mm} \mathrm{Hg}, P<.05)$ within the ischemia-reperfusion region. MT1-MMP activity increased in both regions. Phosphorylated Smad2 increased within the ischemia-reperfusion region. Both in vitro and in vivo interstitial levels of microRNA-133a decreased with ischemia and returned to steadystate levels with reperfusion. In vitro transduction of microRNA-133a in left ventricular fibroblasts decreased MT1-MMP levels.

Conclusions: Modulation of MT1-MMP activity and microRNA-133a exportation into the myocardial interstitium occurred in the setting of acute myocardial ischemia-reperfusion. In addition, changes in microRNA-133a expression in left ventricular fibroblasts resulted in an inverse modulation of MT1-MMP abundance. Therefore, targeting of microRNA-133a represents a potentially novel means for regulating the cascade of profibrotic events after ischemia-reperfusion. (J Thorac Cardiovasc Surg 2013;145:267-77)

\section{Supplemental material is available online.}

From the Division of Cardiothoracic Surgery, ${ }^{\mathrm{a}}$ Medical University of South Carolina, and Ralph H. Johnson Veterans Affairs Medical Center, Charleston, SC; and Divi-

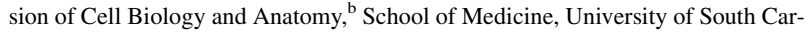
olina, Columbia, SC.

This work was supported by National Institute of Health Grants HL057952, HL059165, and HL095608, and a Merit Award from the Veterans' Affairs Health Administration. S.R.E. was supported by National Institute of Health Grant T32 HL007260.

Disclosures: Authors have nothing to disclose with regard to commercial support.

Read at the 92nd Annual Meeting of The American Association for Thoracic Surgery, San Francisco, California, April 28-May 2, 2012.

Received for publication March 1, 2012; revisions received Aug 29, 2012; accepted for publication Sept 26, 2012; available ahead of print Oct 29, 2012.

Address for reprints: Jeffrey A. Jones, PhD, Cardiothoracic Surgery Research, Strom Thurmond Research Center, 114 Doughty St, Suite 326, Charleston, SC 29425 (E-mail: jonesja@musc.edu).

0022-5223/\$0.00

Published by Elsevier Inc. on behalf of The American Association for Thoracic Surgery

http://dx.doi.org/10.1016/j.jtcvs.2012.09.071
Restoration of blood flow, or reperfusion, after myocardial ischemia can trigger a number of biological responses, including induction of the matrix metalloproteinases (MMPs), which can culminate in ischemia-reperfusion (I/R) injury and myocardial dysfunction. ${ }^{1-3}$ One particular MMP, membrane type 1 MMP (MT1-MMP), has been implicated in remodeling of the extracellular matrix (ECM) and is up-regulated in animal models of $\mathrm{I} / \mathrm{R} \cdot{ }^{1-6}$ However, upstream regulation of MT1-MMP remains unknown. The microRNAs (miRs) play a role in regulating MT1-MMP expression by inhibiting translation or stimulating mRNA degradation. $^{7}$ For example, changes in myocardial miR-29a levels were associated with ECM remodeling in the setting of $\mathrm{I} / \mathrm{R} .{ }^{8}$ Furthermore, changes in miR-133a levels were associated with modulation of ECM collagen. ${ }^{9,10}$ With the use of in silico mapping studies, a putative miR-133a binding site in the MT1-MMP transcript and in the transcripts of other members of the transforming growth factor-beta (TGF- $\beta)$ pathway was identified. ${ }^{11-13}$ In 


$$
\begin{aligned}
& \text { Abbreviations and Acronyms } \\
& \text { ANOVA }=\text { analysis of variance } \\
& \text { ECM }=\text { extracellular matrix } \\
& \text { FGM }=\text { fibroblast growth medium } \\
& \text { I/R }=\text { ischemia-reperfusion } \\
& \text { LTBP-1 }=\text { latent transforming growth factor } \\
& \quad \text { binding protein } 1 \\
& \text { LV }=\text { left ventricular } \\
& \text { miR }=\text { microRNA } \\
& \text { MMP }=\text { matrix metalloproteinase } \\
& \text { MT1- }=\text { membrane type } 1 \text { matrix } \\
& \text { MMP } \text { metalloproteinase } \\
& \text { PCR }= \text { polymerase chain reaction } \\
& \text { pSmad2 } \text { phosphorylated Smad2 } \\
& \text { rPRSW }= \text { regional preload recruitable stroke } \\
& \text { work } \\
& \text { TGF- } \beta= \text { transforming growth factor-beta } \\
& \text { TGF- }= \text { transforming growth factor beta } \\
& \beta \text { R1 } \text { receptor } 1 \\
& \text { UTR }= \text { untranslated region }
\end{aligned}
$$

addition, MT1-MMP may contribute to TGF- $\beta$ activation through proteolysis of latent transforming growth factor binding protein 1 (LTBP-1). ${ }^{2,3,14}$ LTBP-1 proteolysis releases TGF- $\beta$, which promotes phosphorylation of Smads (Smad2) and downstream transcription of type I collagen. ${ }^{15,16}$ However, whether activation of TGF- $\beta$ signaling cascade occurs with acute myocardial I/R injury has not been established. Therefore, this study tested the hypothesis that changes in miR-133a expression/abundance occur with acute myocardial I/R, coincident with time- and region-dependent changes in MT1-MMP substrate processing and activation of profibrotic pathways.

\section{MATERIALS AND METHODS \\ Model of Ischemia-Reperfusion}

Yorkshire pigs ( $\mathrm{n}=12,30$ to $35 \mathrm{~kg}$; Hambone Farms, Orangeburg, SC) were instrumented for transient coronary artery occlusion. ${ }^{1,2}$ Briefly, a pair of sonomicrometry crystals and microdialysis probes were placed within the $\mathrm{I} / \mathrm{R}$ region (posterior left ventricular $[\mathrm{LV}]$ wall) and in a defined remote region (anterior apical LV). Regional preload recruitable stroke work (rPRSW) was determined. ${ }^{1}$ After steady state, ischemia was induced for 90 minutes and then released for 120 minutes of reperfusion, and rPRSW was measured at 30-minute intervals. After the I/R protocol, the LV free wall was harvested for biochemical analysis. Pigs with no I/R $(n=5)$ were included as referent controls. Animals were treated and cared for in accordance with the National Institutes of Health Guide for the Care and Use of Laboratory Animals (National Institutes of Health, 1996). Additional information is provided in the Online Supplemental Methods.

\section{Microdialysis and Fluorogenic Substrate \\ Measurements}

Microdialysis probes (20 kDa; CMA/Microdialysis, North Chelmsford, Mass) were placed in the mid-myocardium, and quenched fluorogenic peptides containing an artificial MT1-MMP-specific hydrolysis site or an endogenous MT1-MMP hydrolysis site from LTBP-1 were infused (3 $\mu \mathrm{L} / \mathrm{min}$ ) as previously described. ${ }^{1,3,17,18}$ Interstitial MT1-MMP activity or LTBP-1 hydrolysis was determined as a function of the fluorescence in the dialysate.

\section{Immunoblotting}

Immunoblotting was performed to determine myocardial levels of phosphorylated Smad2 (pSmad2) and Smad2 (antibodies 3101 and 5339, respectively; Cell Signaling, Danvers, Mass) and MT1-MMP (AB8221; Millipore, Billerica, Mass). ${ }^{1}$ The immunoreactive signals were analyzed using densitometric methods.

\section{mRNA Quantification}

Myocardial mRNA levels were determined using real-time polymerase chain reaction (PCR). Primer/probe sets were synthesized for porcine LTBP-1 and TGF- $\beta$ receptor 1 (TGF- $\beta$ R1), and purchased for MT1MMP, MMP-9, type I collagen, and 18S rRNA (cat. no. Ss0339441_ml, Ss03392098_m1, Ss03373340_m1, and Hs99999901_s1, respectively; Applied Biosystems, Foster City, Calif).

\section{Bioinformatics Analysis of microRNA-133a}

In silico mapping of the $3^{\prime}$ untranslated region (UTR) of the human MT1-MMP gene (TargetScan Human 5.1, www.targetscan.org) identified a high-probability target for miR-133a (context score $-0.17, \mathrm{P}_{\mathrm{Ct}}$ $0.34) .{ }^{11-13,19}$ Of note, the 8-mer seed sequence was perfectly replicated in the $3^{\prime}$-UTR of the porcine MT1-MMP gene. Moreover, when the human and porcine $3^{\prime}$-UTRs of MT1-MMP are aligned (ClustalW2; http://www. ebi.ac.uk/Tools/msa/ clustalw2/), the miR-133a target nucleotide sequence matches with identity at 25 of 31 base pairs, suggesting that porcine MT1MMPs also possess a high-fidelity target site for miR-133a. In similar fashion, miR-133a putatively targets several other genes that play an important role in the profibrotic response, including MMP-9, LTBP-1, TGF- $\beta$ R 1, and type I collagen. ${ }^{9,10,13}$

\section{microRNA Quantification}

miR levels were determined in myocardial homogenates, microdialysate samples, and conditioned media samples $(100 \mu \mathrm{L})$ from the in vitro studies. Isolated RNA was reverse transcribed, and expression levels of miR-133a and miR-29a were determined.

\section{Simulated Ischemia-Reperfusion in Porcine Left Ventricular Fibroblasts}

Porcine LV fibroblasts were incubated for 120 minutes in normoxic medium $\left(\mathrm{O}_{2}\right.$ tension $>250$ Torr $) .{ }^{20}$ The dishes were then incubated in hypoxic medium $(2 \mathrm{~mL})$, which was infused with $95 \%$ nitrogen, $5 \% \mathrm{CO}_{2}$ for 30 minutes $\left(\mathrm{O}_{2}\right.$ tension $<50$ Torr $)$. Next, the cells were reincubated in normoxic medium for 120 minutes. Conditioned medium was collected at the end of each defined period and assayed by real-time polymerase chain reaction for exported miRs. ${ }^{21}$

\section{In Vitro Membrane Type 1 Matrix Metalloproteinase Protein Modulation}

Human LV myocardial fibroblasts $\left(2 \times 10^{5}\right.$ cells, $\left.\mathrm{n}=3\right)$ were transduced with 1 of 2 lentiviral vectors to overexpress miR-133a (pMIRNA1-hsa-miR-133a-1) and for knockdown of miR-133a (pmiRZip-hsa-miR-133a-1; both System Biosciences, Mountain View, Calif). Five days after transduction, the fibroblasts were collected for determination of MT1-MMP protein levels.

\section{Data Analysis}

LV regional function and hemodynamics were compared between groups by analysis of variance (ANOVA). Interstitial MT1-MMP activity 

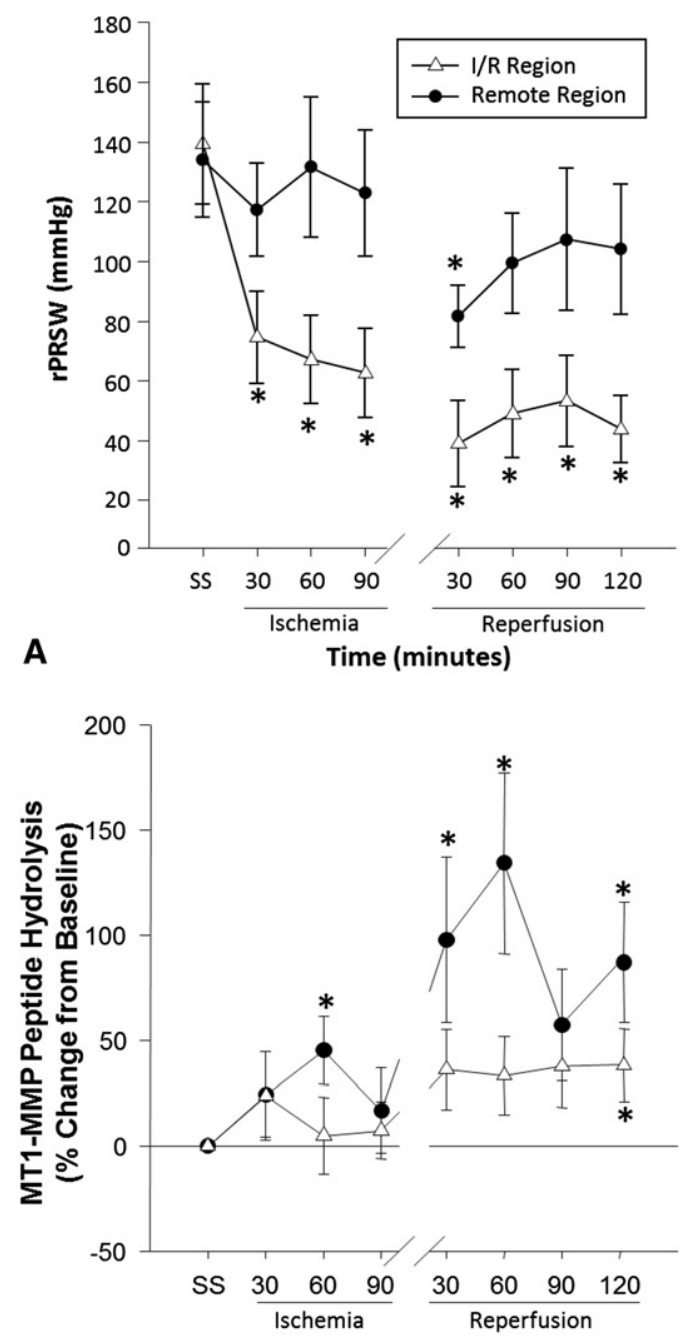

B

Time (minutes)

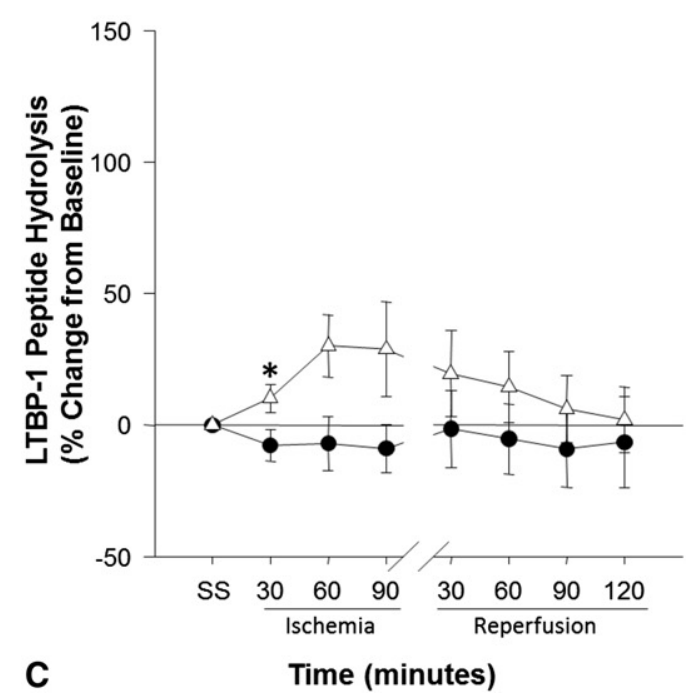

FIGURE 1. A, Regional myocardial contractile function. Timedependent rPRSW was determined in the remote (solid dot) and $\mathrm{I} / \mathrm{R}$ (open triangle) regions. A time- and region-dependent difference was and LTBP-1 substrate hydrolysis were expressed as a percent change from steady-state values (steady-state set to 0 ). The integrated optical density values for $\mathrm{pSmad} 2$, Smad2, and MT1-MMP were expressed as a percent of controls and compared using a 1-sample $t$ test. Levels of miRs and mRNA expression levels were normalized to $18 \mathrm{~S}$ or Caenorhabditis elegans miR-39 values, as appropriate, and compared as a fold change from control values by the $\Delta \Delta \mathrm{Ct}$ method. ${ }^{22}$ Post hoc mean separation after each ANOVA was performed using Bonferroni-adjusted pairwise comparisons. Statistical analyses were performed using STATA statistical software (StataCorp, College Station, Tex). Results are presented as the mean \pm standard error of the mean.

\section{RESULTS}

LV function and hemodynamics at steady state and with $\mathrm{I} / \mathrm{R}$ are summarized in Table E1. Although heart rate increased during reperfusion, ${ }^{1,2} \mathrm{LV}$ peak systolic and mean arterial pressures remained unchanged with $\mathrm{I} / \mathrm{R}$. This suggests that the $\mathrm{I} / \mathrm{R}$ protocol did not cause significant hemodynamic compromise. However, regional segmental shortening and rPRSW decreased in the I/R region with ischemia and remained decreased during reperfusion (Table E1 and Figure 1, A, respectively). Interstitial MT1MMP activity increased over time in both the I/R and remote regions (Figure 1, B). However, interstitial MT1MMP-mediated LTBP-1 substrate hydrolysis increased only within the $\mathrm{I} / \mathrm{R}$ region (Figure $1, C$ ).

Total Smad2 abundance increased in the I/R region after $\mathrm{I} / \mathrm{R}$ (Figure 2, A). A small increase in pSMAD2 was measured in the remote region, whereas a robust increase was observed in the I/R region after I/R $(P<.05$ vs referent control) (Figure 2, A).

Myocardial mRNA levels of essential ECM-modifying genes after I/R injury are shown in Figure 2, B. Relative mRNA levels of MT1-MMP, MMP-9, LTBP-1, TGF- $\beta$ R1, and COL1A1 were increased within the I/R region, whereas LTBP-1, TGF- $\beta$ R1, and MT1-MMP mRNA levels were increased in the remote region.

With ischemia, interstitial miR-133a levels decreased in the both the I/R region and the remote region (Figure 3, $A$, top and bottom). With reperfusion, interstitial miR133a levels returned to steady state within the I/R region and remained decreased in the remote region. Interstitial miR-29a levels remained unchanged in either region with $\mathrm{I} / \mathrm{R}$ (Figure 3, B, top and bottom). At the completion of $\mathrm{I} / \mathrm{R}$, total myocardial miR-133a and miR-29a levels were similar in the remote region, $\mathrm{I} / \mathrm{R}$ region, and referent

observed (ANOVA; $\mathrm{F}=3.82$ and $\mathrm{F}=27.74$, respectively; $P<.01$ ). B, MT1-MMP-specific fluorogenic peptide hydrolysis. A time- and regiondependent difference was observed (ANOVA; $\mathrm{F}=9.50$ and $\mathrm{F}=3.33$, respectively; $P<.05)$. C, LTBP-1 substrate hydrolysis. A regiondependent difference was observed (ANOVA, $\mathrm{F}=10.20, P<.05$ ). $* P<$ .05 versus steady state. $I / R$, Ischemia-reperfusion; $r P R S W$, regional preload recruitable stroke work; $M T 1-M M P$, membrane type 1 matrix metalloproteinase; $L T B P-1$, latent transforming growth factor binding protein 1 . 

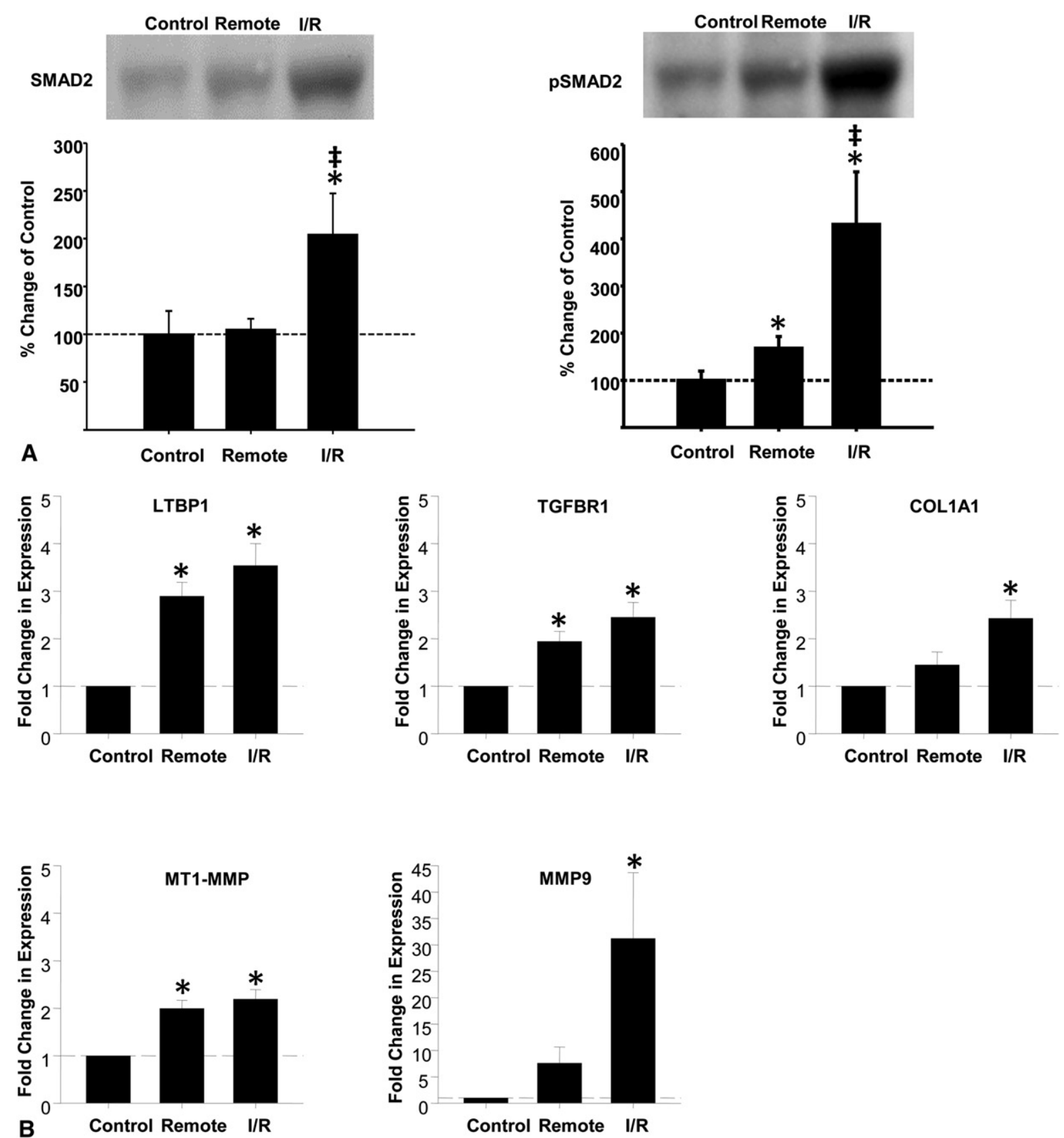

FIGURE 2. Activation of TGF- $\beta$ signaling pathway. A, Immunoblotting total Smad 2 and $\mathrm{pSmad} 2$ in the remote region, I/R region, and controls $(\mathrm{n}=5)$. $* P<.05$ versus control. $\ddagger P<.05$ versus remote region. B, Myocardial mRNA levels for MMP9, MT1-MMP, LTBP1, TGF- $\beta$ R1, and COL1A1 (type I collagen) in the remote region, I/R region, and controls. A region-dependent difference was observed (ANOVA; $F=4.45, F=14.37, F=14.62, F=9.69, F=6.48$, respectively; all $P<.05)$. $* P<.05$ versus control. IR, Ischemia-reperfusion; $L T B P 1$, latent transforming growth factor binding protein $1 ; M M P 9$, matrix metalloproteinase 9; MT1-MMP, membrane type 1 matrix metalloproteinase; $p S M A D 2$, phosphorylated Smad2; TGF- $\beta R 1$, transforming growth factor beta receptor 1.

controls $(\Delta \Delta \mathrm{Ct}$; miR-133a $0.99 \pm 0.67$ and $1.22 \pm 0.96$, respectively, $P=.50 ; \Delta \Delta \mathrm{Ct} ; \mathrm{miR}-29 \mathrm{a} 1.12 \pm 0.51$ and $1.18 \pm$ 0.62 , respectively, $P=.78$ ). With simulated I/R, levels of miR-133a in the conditioned medium decreased with hypoxia $(P=.047)$ and returned to steady state after reperfusion (Figure 4, $A$ ).

In normal human LV fibroblasts, overexpression of miR133a caused a reduction in MT1-MMP protein levels
(Figure 4, B). Conversely, knockdown of miR-133a by anti-miR-133a caused an increase in MT1-MMP protein abundance.

\section{DISCUSSION}

Myocardial I/R can elicit a number of cellular and extracellular events, including contractile dysfunction, localized release of bioactive molecules, and induction of proteolytic 

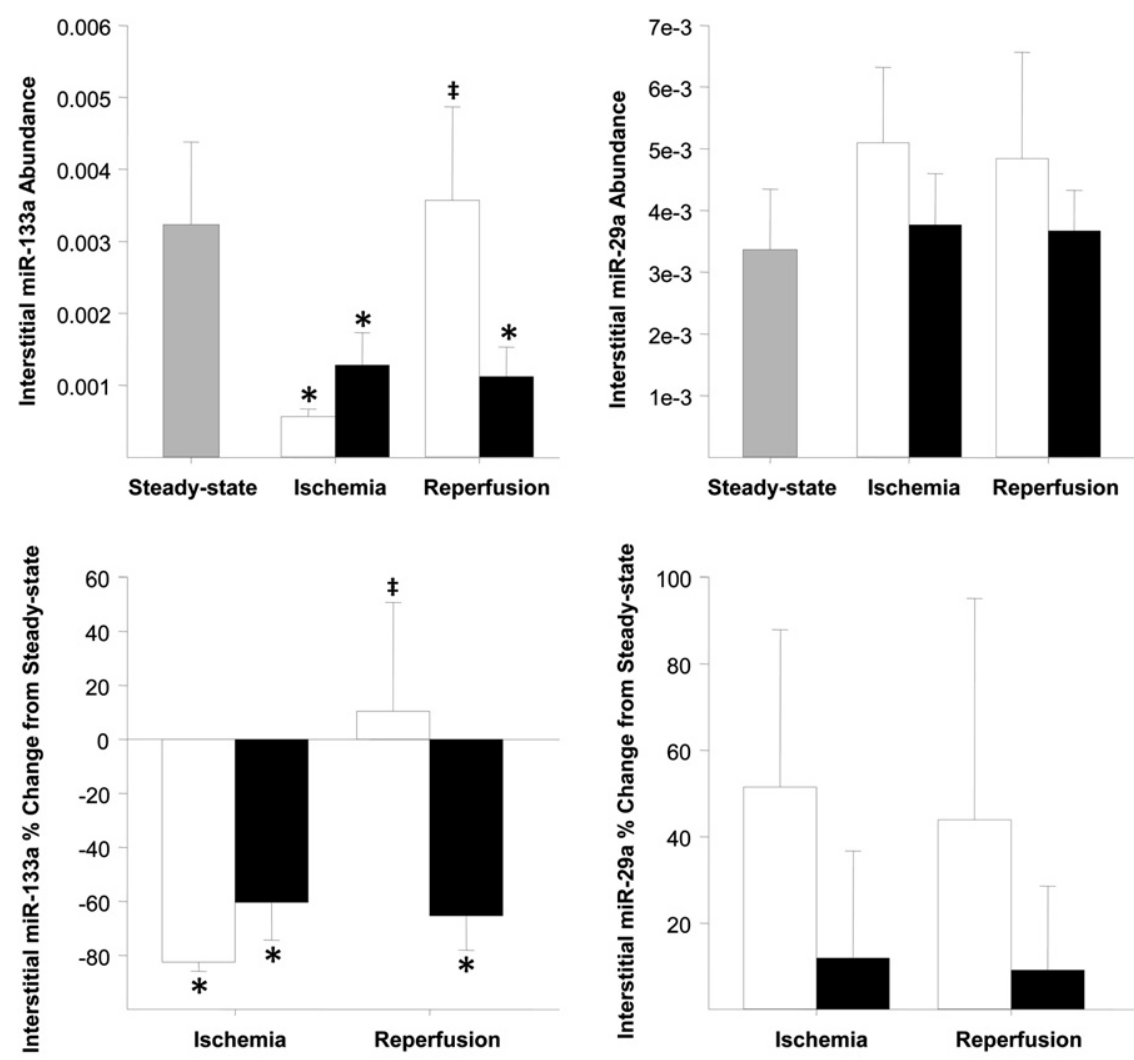

A

B

FIGURE 3. Interstitial miR levels. Interstitial levels of miR-133a and miR-29a were measured at steady state ( gray), ischemia, and after reperfusion for the I/R (white) and remote (black) regions. Top: absolute values. Bottom: Data are depicted as a percent change from steady state. A, Interstitial miR-133a. A time-dependent difference was observed (steady-state miR-133a $=3.23 \times 10^{-3} \pm 1.15 \times 10^{-3}$; ANOVA; $\mathrm{F}=3.50 ; P<.05$ ). B, Interstitial miR-29a. No change with $\mathrm{I} / \mathrm{R}$ was observed (ANOVA, $\mathrm{F}=0.39, P<.68$ ). ${ }^{*} P<.05$ versus steady state. $\ddagger P<.05$ versus ischemia. miR, MicroRNA.

pathways, which includes changes in MT1-MMP abundance and activity. ${ }^{1,2}$ The miRs are a major determinant of post-transcriptional regulation; certain miRs, such as miR-133a and miR-29a, have been identified as important mediators in ECM remodeling in the setting of $\mathrm{I} / \mathrm{R} .^{8-10}$ Accordingly, this study tested the hypothesis that changes in miR-133a regulation occur with acute myocardial I/R injury, which contributes to time- and region-dependent changes in MT1-MMP activity processing of MT1-MMP substrates. The significant findings of the present study are as follows: (1) The contractile deficit that occurred with $\mathrm{I} / \mathrm{R}$ was associated with increased MT1-MMP activity in both the remote and I/R regions and increased hydrolysis of the MT1-MMP substrate, LTBP-1, in only the I/R region. Concomitantly, there were differential and dynamic changes in interstitial levels of miR-133a without a change in the total myocardial pool of miR-133a during I/R. (2) Simulated $\mathrm{I} / \mathrm{R}$ in myocardial fibroblasts recapitulated the in vivo changes in miR-133a levels, suggesting a direct role for $\mathrm{I} / \mathrm{R}$ in the exportation of miR-133a. (3) miR-133a transduction in myocardial fibroblasts resulted in a decrease in MT1-MMP protein levels. (4) There was an acute activation of the TGF- $\beta$ signaling pathway, components of which include many targets of miR-133a. Therefore, these findings suggest that changes in miR-133a levels during acute $\mathrm{I} / \mathrm{R}$ may potentiate long-term sequelae of TGF- $\beta$ signaling with respect to myocardial fibrosis and remodeling. Thus, modulation of miR-133a represents a potentially novel molecular target for regulating a cascade of TGF- $\beta$ mediated profibrotic events after $\mathrm{I} / \mathrm{R}$.

Coronary revascularization after acute coronary syndrome is accompanied by I/R injury, which can result in regional contractile dysfunction that gives rise to altered stress/strain patterns during the cardiac cycle, as well as the acute elaboration of a number of bioactive molecules. ${ }^{2,23}$ These multifactorial changes lead to LV remodeling, characterized by LV dilation and alterations in the content and composition of the myocardial ECM. ${ }^{1,23,24}$ In the present study, regional contractile dysfunction occurred with $\mathrm{I} / \mathrm{R}$ within the $\mathrm{I} / \mathrm{R}$ region and transiently in the remote region. The finding of persistent contractile dysfunction despite reperfusion within the $\mathrm{I} / \mathrm{R}$ region and activation of a key proteolytic pathway mediated by MT1MMP is consistent with past studies. ${ }^{1,2,23}$ The present 

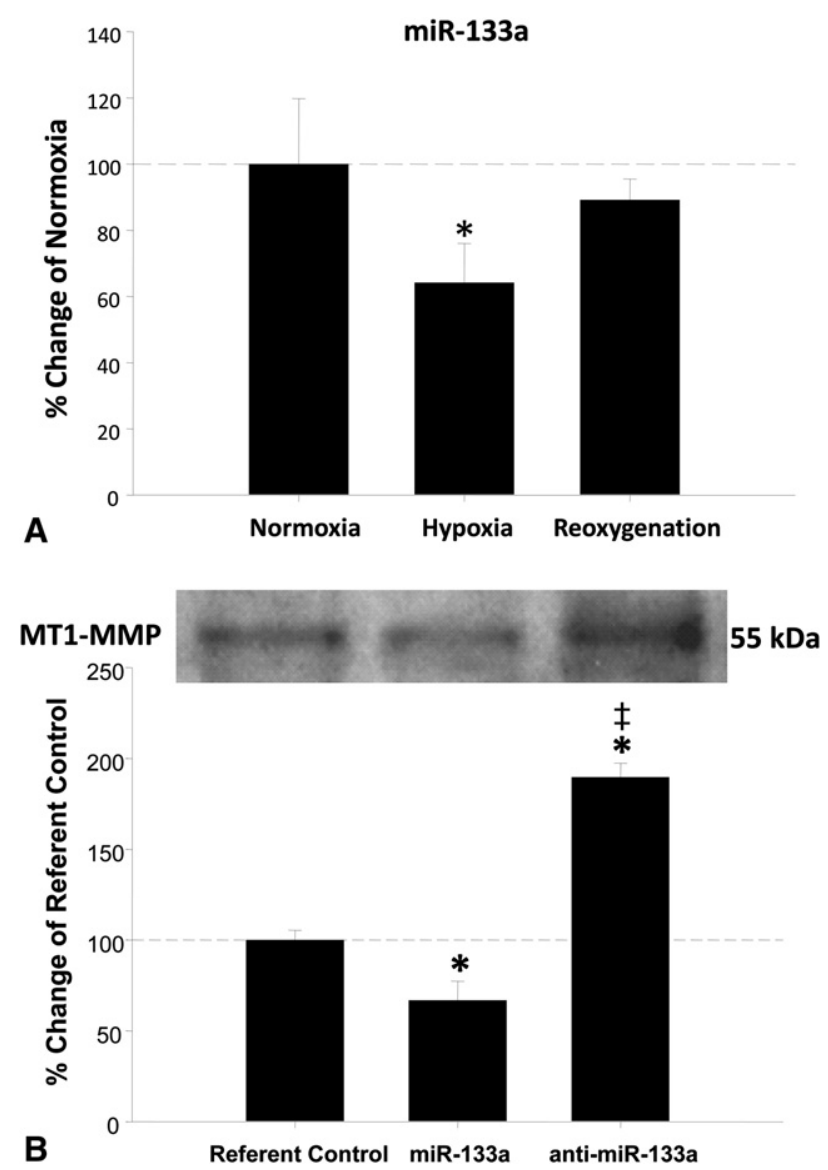

FIGURE 4. In vitro studies. A, Levels of miR-133a in conditioned medium from porcine $\mathrm{LV}$ fibroblast cultures $(\mathrm{n}=3)$ under normoxia, hypoxia, and reoxygenation as a function of normoxia levels. B, MT1-MMP protein abundance in normal human LV fibroblast cultures $(\mathrm{n}=3) 5$ days after transduction with miR-133a or anti-miR-133a as a percent change from referent control values. $* P<.05$ versus steady state. $\ddagger P<.05$ versus ischemia. $m i R$, MicroRNA; MT1-MMP, membrane type 1 matrix metalloproteinase.

study builds on these past reports by demonstrating that key upstream regulators and downstream effectors of altered MT1-MMP activity are induced acutely with I/R. Specifically, processing of proteins that contribute to fibrosis (LTBP- 1 and TGF- $\beta$ ) and changes in interstitial miR content was altered in the setting of $\mathrm{I} / \mathrm{R}$. However, it must be recognized that alterations in loading conditions also may have served as a stimulus for increased MT1-MMP activity and LTBP-1 substrate hydrolysis at the I/R region. First, changes in mechanical loading can alter MT1-MMP induction. ${ }^{25-28}$ For instance, mechanical stretch of murine aortic rings increased activation of the MT1-MMP gene promoter. ${ }^{27}$ Likewise, increased mechanical loading of papillary muscles increased MT1-MMP expression. ${ }^{28}$ Second, changes in mechanical loading can change the conformation of the cell surface integrins, which in turn may induce a conformational change in LTBP-1 through its integrin binding site and release of TGF- $\beta .^{29}$ The source of acute changes in interstitial MT1-MMP activity notwithstanding, the results from the present study demonstrate that long-term sequelae of $\mathrm{I} / \mathrm{R}$, with respect to changes in contractile function and LV remodeling, are likely initiated by these molecular events in the early I/R period.

The miRs, which are post-transcriptional regulatory molecules, contribute to modulation of ECM remodeling through regulation of processes, which in turn, contribute to fibrosis and ECM degradation. ${ }^{8-10}$ For example, overexpression of miR-133a decreased collagen production in cardiac fibroblasts. ${ }^{9}$ In mice with cardiac-restricted miR133a overexpression, myocardial fibrosis was attenuated in the setting of pressure overload hypertrophy. ${ }^{10}$ Also, miR29a knockdown was associated with increased mRNA expression of fibrillar collagen in mice and a reduction of infarct size in rats. ${ }^{8,30}$ An association between miR-133a and several MMPs has been described in the setting of hematologic and cardiovascular diseases. ${ }^{30-35}$ For example, a down-regulation of miR-133a was associated with increased plasma levels of several MMP types in patients. ${ }^{35}$ With the development of ischemic heart disease, past studies have reported a decrease in miR-133a and an increase in MT1-MMP protein abundance. ${ }^{1,31,34}$ Taken together, the findings from these past studies and results from mapping of a binding site for miR-133a on the MT1-MMP transcript formed the rationale for examining the posttranscriptional regulation of MT1-MMP by miR-133a in the context of myocardial I/R injury. The present study builds on these past reports by demonstrating that myocardial fibroblasts synthesize and release miR-133a and that changes in miR-133a levels can modulate MT1MMP protein abundance. Specifically, MT1-MMP abundance was reduced after miR-133a overexpression in LV fibroblasts, and conversely, MT1-MMP abundance increased after LV fibroblasts were transduced with antimiR-133a. Together, these findings suggest a role for miR-133a-mediated regulation of MT1-MMP abundance (Figure 5) in the context of myocardial I/R.

Past in vitro studies have reported that miRs may be imported/exported from cells, ${ }^{21}$ and a recent study reported changes in total miR-133a levels in a rodent model of $\mathrm{I} / \mathrm{R} \cdot{ }^{36}$ Building on these past findings, the present study demonstrated that a quantifiable pool of miR-133a and miR-29a was present in the myocardial interstitium. In addition, interstitial miR-133a levels changed while the total myocardial pool of miR-133a remained unaltered, suggesting that miR exportation is regulated with I/R (Figure 5). Of note, interstitial levels of miR-29a remained unchanged in the setting of $\mathrm{I} / \mathrm{R}$, suggesting that miR-133a export is selective and $\mathrm{I} / \mathrm{R}$ specific. To examine this further, primary porcine LV fibroblasts were exposed to a simulated I/R protocol, and miR133a within the conditioned media decreased with hypoxia and returned to steady-state levels with reoxygenation, in concordance with the in vivo microdialysis findings. 


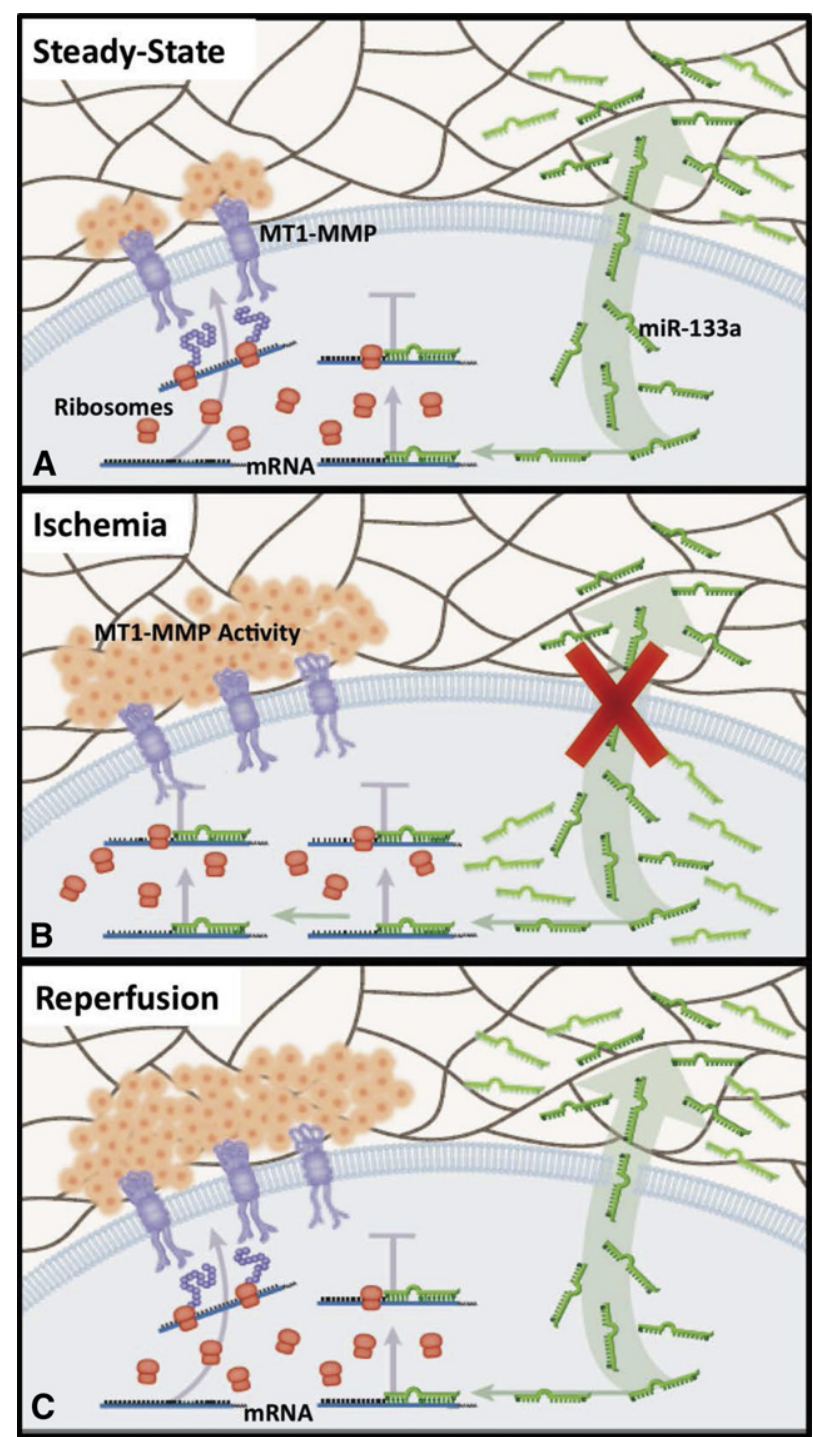

FIGURE 5. Working hypothesis regarding MT1-MMP activation and changes in interstitial miR-133a with I/R. A, At steady state, MT1-MMP mRNA is translated and ultimately transported to the membrane, yielding a competent transmembrane protease. The present study identified a measurable amount of miR-133a exportation into the myocardial interstitial space, and MT1-MMP protein abundance can be regulated by miR-133a. $\mathrm{B}$, With acute ischemia, interstitial MT1-MMP activity increases, likely because of increased trafficking to the membrane. ${ }^{1}$ Interstitial miR-133a levels decreased, suggesting decreased exportation and increased intracellular concentrations, where post-transcriptional regulation of its targets can occur. C, With subsequent reperfusion, interstitial MT1-MMP activity remained increased while interstitial miR-133a returned to steady-state levels within the $\mathrm{I} / \mathrm{R}$ region, but exportation was not restored in the remote region. Therefore, increased miR-133a exportation within the I/R region during reperfusion (ie, a decrease in the intracellular pool of miR-133a) would relieve translational repression of miR-133a targets, including those involved with the TGF- $\beta$ signaling pathway. $m i R$, MicroRNA; MT1-MMP, membrane type 1 matrix metalloproteinase.
Therefore, the present study provides evidence that differential and dynamic changes in extracellular miR content occur in the setting of acute myocardial $\mathrm{I} / \mathrm{R}$.

It is important to note that miRs or closely related miR families can target multiple mRNA transcripts involved in common biological signaling cascades. ${ }^{37}$ For example, in silico mapping studies of miR-133a have demonstrated several putative targets involved in both ECM degradation, such as MMP-9 and MT1-MMP, and TGF- $\beta$-mediated fibrosis, such as MT1-MMP, LTBP-1, COL1A1, and TGF- $\beta$ R1. In animal and clinical studies, an abundance of several MMPs is generally increased with myocardial ischemia, specifically MMP-9 and MT1-MMP. ${ }^{1,2,38}$ Although changes in levels of both MMP-9 and MT1-MMP are generally associated with inflammatory cell infiltration, both can be produced by endogenous cells resident in the myocardium and are involved in a number of proteolytic events within the ECM. ${ }^{1-4,6,14,24}$ For example, MT1-MMP is a membrane-bound MMP fundamental in activating MMP-2 at the cell surface, ${ }^{5}$ and previous large animal studies have measured increased MT1-MMP with I/R injury. ${ }^{1,2}$ MT1-MMP also is involved in pericellular proteolysis and the release of ECM growth factors from sequestration sites. ${ }^{4}$ In the present study, interstitial MT1-MMP activity was increased in both the $\mathrm{I} / \mathrm{R}$ and the remote regions. In a past study that examined the effects of an antecedent MI that was followed by acute $\mathrm{I} / \mathrm{R}$ injury at the site remote from the original MI, interstitial MT1-MMP activity within the remote myocardial region remained unaltered for the duration of the $\mathrm{I} /$ $\mathrm{R}$ period. ${ }^{2}$ In contrast, a small, but significant, increase in MT1-MMP activity within the remote region during the I/ $\mathrm{R}$ period was observed in the present study. However, it must be recognized that there are at least 2 differences with respect to the experimental design between these 2 studies: First, the coronary artery bed perfusing the "remote" myocardial region was different between the 2 studies. Specifically, the remote region was perfused by the left anterior descending coronary artery in the present study and through the circumflex arterial system in the past study. ${ }^{2} \mathrm{~A}$ second, and perhaps more important, difference was the time that ischemia was maintained. In the past study, ischemia was maintained for 60 minutes as opposed to the 90minute ischemic period in the present study. ${ }^{2}$ Although this remains speculative, it is possible that the increase in ischemic time may have been sufficient to manifest in detectable changes in MT1-MMP activity within the remote myocardial region. Indeed, long-term ischemia (ie, myocardial infarction, as demonstrated in the same past study) was associated with increased MT1-MMP activity in the region remote from the MI. ${ }^{2}$ Therefore, the difference with respect to induction of MT1-MMP activity within the remote region between the 2 studies may have been due to regional differences, as well as the time for which ischemia was maintained. Nevertheless, the present study demonstrated that 
after I/R, mRNA levels of MMP-9 and MT1-MMP also were increased, suggesting that acute induction of pathways contributing to ECM proteolysis accompanies I/R. In vitro studies have provided evidence for MT1-MMP-mediated proteolysis of LTBP-1, resulting in the release of TGF and increased activation of profibrotic pathways. ${ }^{3,14}$ In mice with cardiac-restricted overexpression of MT1-MMP, enhanced proteolytic processing of LTBP-1 was reported and associated with elevated TGF- $\beta$-mediated Smad 2 activation and increased myocardial fibrosis. ${ }^{3}$ A novel finding of the present study was that MT1-MMP-mediated LTBP-1 substrate proteolysis increased only in the $\mathrm{I} / \mathrm{R}$ region. This region-dependent MT1-MMP-mediated LTBP-1 substrate proteolysis could set the stage for increased TGF- $\beta$ signaling within the I/R region. Consequently, protein and mRNA levels of components in the TGF- $\beta$ signaling pathway were increased within the I/R region. Specifically, the abundance and phosphorylation of Smad2 (pSmad2) were increased in the $\mathrm{I} / \mathrm{R}$ region concomitant with increased mRNA expression of LTBP-1, TGF- $\beta$ R 1 , and COL1A1. Therefore, these results suggest that an acute, regiondependent activation of TGF- $\beta$ signaling and transcriptional induction of profibrotic molecules occurred with $I / R$ and may promote fibrosis through the subsequent production of ECM proteins. For example, in a pig model of myocardial $\mathrm{I} / \mathrm{R}$, Barallobre-Barreiro and colleagues ${ }^{39}$ reported an increased abundance of fibrillar collagen within the I/R region at 15 and 60 days after the initial ischemic injury. Moreover, previous studies have demonstrated that miR-133a can play a regulatory role in the determination of collagen content and connective tissue growth factor abundance, 2 components that are important in myocardial fibrosis. ${ }^{9,10}$ The present study demonstrated that interstitial signaling in response to $\mathrm{I} / \mathrm{R}$ activates both proteolytic and profibrotic pathways, which are initiated at the time of the acute $\mathrm{I} / \mathrm{R}$ event and can potentiate LV remodeling over time. Specifically, interstitial miR-133a decreased within both the remote and I/R regions with ischemia, suggesting maintenance/increase of intracellular miR-133a, which could attenuate translation of MT1-MMP and the components of the TGF- $\beta$ signaling pathway. ${ }^{9,10}$ With reperfusion, extracellular miR-133a increased from ischemia to reperfusion, suggesting a restoration of miR-133a export (or decrease in intracellular miR-133a) in the I/R region, but not in the remote region (Figure 5). These findings suggest a potential loss of miR-133a-mediated regulation of remodeling processes within the $\mathrm{I} / \mathrm{R}$ region. Therefore, it is likely that the transient changes in miR expression during the $\mathrm{I} / \mathrm{R}$ period, as observed in the present study, set into motion a sequence of events that trigger changes in the abundance/ activity of proteins and activation of signaling cascades that result in a fibrotic response. However, the present study was focused on determining whether changes in miR abundance could be detected within the myocardial interstitium during the acute phase of $\mathrm{I} / \mathrm{R}$, and not on long-term evaluation of interstitial miR-133a and its downstream targets. Therefore, future studies would be required to determine the effect of the changes in miR-133a levels that occurred with acute I/R on the abundance of myocardial proteins in the ischemic and remote myocardial regions when studied over longer (days/months) reperfusion periods.

The present study is not without limitations. It must be recognized that miR-133a may bind to gene sequences for a number of proteins, including those for MMP-9, MT1MMP, LTBP-1, TGF- $\beta$ R1, TGF- $\beta$, and connective tissue growth factor. ${ }^{11-13}$ Conversely, translation of these proteins also may be regulated by a number of other miRs. ${ }^{37}$ A number of cell types within the myocardium, including myocytes and fibroblasts, are likely sources of miR133a. ${ }^{9,10,36,40}$ The rationale for examining the role of myocardial fibroblasts with respect to changes in MT1MMP and miR-133a with I/R was 2-fold: First, fibroblasts are the most numerous cell type within the myocardium and contribute to myocardial remodeling through the synthesis and release of MMPs, tissue inhibitors of matrix metalloproteases, and components of the ECM. ${ }^{41,42}$ Second, the region of a myocardial infarct is often densely populated with fibroblasts because of loss of myocytes secondary to ischemic injury. ${ }^{43}$ The in vitro studies using simulated hypoxia-reoxygenation in isolated myocardial fibroblasts recapitulated the in vivo findings of $\mathrm{I} / \mathrm{R}$ with respect to changes in miR-133a levels. This finding suggests that myocardial fibroblasts contributed, at least in part, to changes in interstitial levels of miR-133a with I/R. Finally, on the basis of the finding that no differences in the total pool of miR levels were noted among the remote region, I/R region, and control myocardium, changes in interstitial miR-133a levels likely reflected changes in intracellular miR-133a levels. However, whether changes in interstitial miR levels occurred because of changes in viability of cells in the $\mathrm{I} / \mathrm{R}$ region was not determined.

\section{CONCLUSIONS}

The findings of the present study demonstrated I/R-dependent changes in MT1-MMP activity and TGF- $\beta$ signaling. These changes coincided with dynamic alterations in miR-133a exportation into the myocardial interstitium and may identify miR-133a as a novel target for modulating the long-term sequelae that develop after a clinically relevant $\mathrm{I} / \mathrm{R}$ event.

\section{References}

1. Deschamps AM, Yarbrough WM, Squires CE, Allen RA, McClister DM, Dowdy KB, et al. Trafficking of the membrane type-1 matrix metalloproteinase in ischemia and reperfusion: relation to interstitial membrane type-1 matrix metalloproteinase activity. Circulation. 2005;111:1166-74.

2. Dixon JA, Gaillard WF 2nd, Rivers WT, Koval CN, Stroud RE, Mukherjee R, et al. Heterogeneity in MT1-MMP activity with ischemia-reperfusion and previous myocardial infarction: relation to regional myocardial function. Am J Physiol Heart Circ Physiol. 2010;299:H1947-58. 
3. Spinale FG, Mukherjee R, Zavadzkas JA, Koval CN, Bouges S, Stroud RE, et al. Cardiac restricted overexpression of membrane type-1 matrix metalloproteinase causes adverse myocardial remodeling following myocardial infarction. J Biol Chem. 2010;285:30316-27.

4. d'Ortho MP, Will H, Atkinson S, Butler G, Messent A, Gavrilovic J, et al. Membrane-type matrix metalloproteinases 1 and 2 exhibit broad-spectrum proteolytic capacities comparable to many matrix metalloproteinases. Eur J Biochem. 1997; 250:751-7.

5. Knauper V, Will H, Lopez-Otin C, Smith B, Atkinson SJ, Stanton H, et al. Cellular mechanisms for human procollagenase-3 (MMP-13) activation. Evidence that MT1-MMP (MMP-14) and gelatinase a (MMP-2) are able to generate active enzyme. J Biol Chem. 1996;271:17124-31.

6. Spruill LS, Lowry AS, Stroud RE, Squires CE, Mains IM, Flack EC, et al. Membrane-type-1 matrix metalloproteinase transcription and translation in myocardial fibroblasts from patients with normal left ventricular function and from patients with cardiomyopathy. Am J Physiol Cell Physiol. 2007;293:C1362-73.

7. van Rooij E, Olson EN. MicroRNAs: powerful new regulators of heart disease and provocative therapeutic targets. J Clin Invest. 2007;117:2369-76.

8. van Rooij E, Sutherland LB, Thatcher JE, DiMaio JM, Naseem RH, Marshall WS, et al. Dysregulation of microRNAs after myocardial infarction reveals a role of miR-29 in cardiac fibrosis. Proc Natl Acad Sci U S A. 2008;105: 13027-32.

9. Duisters RF, Tijsen AJ, Schroen B, Leenders JJ, Lentink V, van der Made I, et al. miR-133 and miR-30 regulate connective tissue growth factor: implications for a role of microRNAs in myocardial matrix remodeling. Circ Res. 2009;104: 170-8, 6 p following 8 .

10. Matkovich SJ, Wang W, Tu Y, Eschenbacher WH, Dorn LE, Condorelli G, et al. MicroRNA-133a protects against myocardial fibrosis and modulates electrical repolarization without affecting hypertrophy in pressure-overloaded adult hearts. Circ Res. 2010;106:166-75.

11. Friedman RC, Farh KK, Burge CB, Bartel DP. Most mammalian mRNAs are conserved targets of microRNAs. Genome Res. 2009;19:92-105.

12. Grimson A, Farh KK, Johnston WK, Garrett-Engele P, Lim LP, Bartel DP. MicroRNA targeting specificity in mammals: determinants beyond seed pairing. Mol Cell. 2007;27:91-105.

13. Lewis BP, Burge CB, Bartel DP. Conserved seed pairing, often flanked by adenosines, indicates that thousands of human genes are microRNA targets. Cell. 2005; 120:15-20.

14. Tatti O, Vehvilainen P, Lehti K, Keski-Oja J. MT1-MMP releases latent TGFbeta1 from endothelial cell extracellular matrix via proteolytic processing of LTBP-1. Exp Cell Res. 2008;314:2501-14.

15. Roberts AB, Sporn MB, Assoian RK, Smith JM, Roche NS, Wakefield LM, et al. Transforming growth factor type beta: rapid induction of fibrosis and angiogenesis in vivo and stimulation of collagen formation in vitro. Proc Natl Acad Sci US A. 1986;83:4167-71

16. Wrana JL, Attisano L, Carcamo J, Zentella A, Doody J, Laiho M, et al. TGF beta signals through a heteromeric protein kinase receptor complex. Cell. 1992;71: 1003-14.

17. Karsdal MA, Larsen L, Engsig MT, Lou H, Ferreras M, Lochter A, et al. Matrix metalloproteinase-dependent activation of latent transforming growth factor-beta controls the conversion of osteoblasts into osteocytes by blocking osteoblast apoptosis. J Biol Chem. 2002;277:44061-7.

18. Rodriguez D, Morrison CJ, Overall CM. Matrix metalloproteinases: what do they not do? New substrates and biological roles identified by murine models and proteomics. Biochim Biophys Acta. 2010;1803:39-54.

19. Rehmsmeier M, Steffen P, Hochsmann M, Giegerich R. Fast and effective prediction of microRNA/target duplexes. RNA. 2004;10:1507-17.

20. Flack EC, Lindsey ML, Squires CE, Kaplan BS, Stroud RE, Clark LL, et al. Alterations in cultured myocardial fibroblast function following the development of left ventricular failure. J Mol Cell Cardiol. 2006;40:474-83.

21. Wang K, Zhang S, Weber J, Baxter D, Galas DJ. Export of microRNAs and microRNA-protective protein by mammalian cells. Nucleic Acids Res. 2010; 38:7248-59.

22. Livak KJ, Schmittgen TD. Analysis of relative gene expression data using realtime quantitative PCR and the 2(-Delta Delta C(T)) Method. Methods. 2001; 25:402-8.

23. Chapman RE, Spinale FG. Extracellular protease activation and unraveling of the myocardial interstitium: critical steps toward clinical applications. Am J Physiol Heart Circ Physiol. 2004;286:H1-10.

24. Spinale FG. Myocardial matrix remodeling and the matrix metalloproteinases: influence on cardiac form and function. Physiol Rev. 2007;87:1285-342.
25. Guo C, Piacentini L. Type I collagen-induced MMP-2 activation coincides with up-regulation of membrane type 1-matrix metalloproteinase and TIMP-2 in cardiac fibroblasts. J Biol Chem. 2003;278:46699-708.

26. Kim JI, Cordova AC, Hirayama Y, Madri JA, Sumpio BE. Differential effects of shear stress and cyclic strain on Sp1 phosphorylation by protein kinase Czeta modulates membrane type 1-matrix metalloproteinase in endothelial cells. Endothelium. 2008;15:33-42.

27. Ruddy JM, Jones JA, Stroud RE, Mukherjee R, Spinale FG, Ikonomidis JS. Differential effects of mechanical and biological stimuli on matrix metalloproteinase promoter activation in the thoracic aorta. Circulation. 2009;120(11 Suppl):S262-8.

28. Zile MR, Baicu CF, Stroud RE, Van Laer A, Arroyo J, Mukherjee R, et al. Pressure overload-dependent membrane type 1-matrix metalloproteinase induction: relationship to LV remodeling and fibrosis. Am J Physiol Heart Circ Physiol. 2012;302:H1429-37.

29. Fontana L, Chen Y, Prijatelj P, Sakai T, Fassler R, Sakai LY, et al. Fibronectin is required for integrin alphavbeta6-mediated activation of latent TGF-beta complexes containing LTBP-1. FASEB J. 2005;19:1798-808.

30. Ye Y, Perez-Polo JR, Qian J, Birnbaum Y. The role of microRNA in modulating myocardial ischemia-reperfusion injury. Physiol Genomics. 2011;43:534-42.

31. Bostjancic E, Zidar N, Stajer D, Glavac D. MicroRNAs miR-1, miR-133a, miR$133 \mathrm{~b}$ and miR-208 are dysregulated in human myocardial infarction. Cardiology. 2010;115:163-9.

32. Ikeda S, Pu WT. Expression and function of microRNAs in heart disease. Curr Drug Targets. 2010;11:913-25.

33. Jones JA, Stroud RE, O'Quinn EC, Black LE, Barth JL, Elefteriades JA, et al. Selective microRNA suppression in human thoracic aneurysms: relationship of miR-29a to aortic size and proteolytic induction. Circ Cardiovasc Genet. 2011; 4:605-13.

34. Tang Y, Zheng J, Sun Y, Wu Z, Liu Z, Huang G. MicroRNA-1 regulates cardiomyocyte apoptosis by targeting Bcl-2. Int Heart J. 2009;50:377-87.

35. Slezak S, Jin P, Caruccio L, Ren J, Bennett M, Zia N, et al. Gene and microRNA analysis of neutrophils from patients with polycythemia vera and essential thrombocytosis: down-regulation of micro RNA-1 and -133a. J Transl Med. 2009;7:39.

36. He B, Xiao J, Ren AJ, Zhang YF, Zhang H, Chen M, et al. Role of miR-1 and miR-133a in myocardial ischemic postconditioning. J Biomed Sci. 2011;18:22.

37. Dorn GW 2nd. MicroRNAs: redefining mechanisms in cardiac disease. J Cardiovasc Pharmacol. 2010;56:589-95.

38. Spinale FG, Koval CN, Deschamps AM, Stroud RE, Ikonomidis JS. Dynamic changes in matrix metalloproteinase activity within the human myocardial interstitium during myocardial arrest and reperfusion. Circulation. 2008;118(14 Suppl):S16-23.

39. Barallobre-Barreiro J, Didangelos A, Schoendube FA, Drozdov I, Yin X, Fernandez-Caggiano $\mathrm{M}$, et al. Proteomics analysis of cardiac extracellular matrix remodeling in a porcine model of ischemia/reperfusion injury. Circulation. 2012; 125:789-802.

40. Jayawardena TM, Egemnazarov B, Finch EA, Zhang L, Payne JA, Pandya K et al. MicroRNA-mediated in vitro and in vivo direct reprogramming of cardiac fibroblasts to cardiomyocytes. Circ Res. 2012;110:1465-73.

41. Brown RD, Ambler SK, Mitchell MD, Long CS. The cardiac fibroblast: therapeutic target in myocardial remodeling and failure. Annu Rev Pharmacol Toxicol. 2005; 45:657-87.

42. Frangogiannis NG, Smith CW, Entman ML. The inflammatory response in myocardial infarction. Cardiovasc Res. 2002;53:31-47.

43. Porter KE, Turner NA. Cardiac fibroblasts: at the heart of myocardial remodeling. Pharmacol Ther. 2009;123:255-78.

\section{Discussion}

Dr Paul W. M. Fedak (Calgary, Alberta, Canada). There is clear clinical evidence that even with early and successful reperfusion after coronary occlusion, patients will undergo progressive cardiac remodeling that can lead to heart failure. The key molecular and cellular changes that occur after reperfusion are not well known. It gives us a window of opportunity where we could potentially treat patients early during or after reperfusion to prevent maladaptive signals from happening, but we need to understand them better. Your work is important because it leads us in 
that direction to better understand mechanistically what is happening with those molecular and cellular changes.

What is unique and important is that you have been able to separate out region- and time-specific changes in a preclinical relevant animal model. What is really important is that you are able to separate ECM interstitial signaling from the cellular changes. It is difficult to present that complexity of data in such a short period of time, and you did a great job. I have a couple of questions for you.

You have designed your experiment to look at mechanistic data and tried to tease out time- and region-specific changes and correlate those events. I note with your data you are trying to correlate MT1-MMP activity and LTB processing, but in the remote area during reperfusion you observed the highest levels of the MMP actively, but you didn't observe the similar changes in the LTB processing. Does that refute your hypothesis?

Dr Eckhouse. I believe the differences seen in MT1-MMP and LTBP-1 activity with microdialysis actually support our hypothesis.

First, in examining MT1-MMP activity with microdialysis during the I/R protocol, there are several possible reasons that could lead to this increased MT1-MMP activity in the remote region. Previous studies from other laboratories have determined that a phosphorylation event occurring at the C-terminus of MT1MMP can lead to a substrate specificity and directed localization within a cell membrane. From these findings, our research group hypothesizes that post-translational modifications of MT1-MMP in vivo are promoting increased cleavage of the MT1-MMP fluorogenic peptide in a region-dependent manner.

An important question to consider is how are the MT1-MMP and LTBP-1 substrates different? The peptide sequences of each substrate are different. The MT1-MMP fluorogenic peptide is a synthetic amino acid sequence that is hydrolyzed specifically by MT1-MMP in vitro and in vivo. Previous validation studies confirmed that the amino acid sequence is specific for MT1MMP over other MMPs. The LTBP-1 fluorogenic peptide represents an endogenous substrate sequence that is hydrolyzed by MT1-MMP. Previous in vivo studies have determined that with overexpression of MT1-MMP, there is a decrease in full-length LTBP-1 and an increase in the low-molecular-weight split products of LTBP-1 after MT1-MMP-mediated hydrolysis. Therefore, MT1-MMP differentially processes the 2 synthetic peptides.

The cleavage of the LTBP-1 fluorogenic peptide was specific to the $\mathrm{I} / \mathrm{R}$ region, which is supported by the increase in the activation of the TGF- $\beta$ profibrotic pathway as measured by pSmad 2 in the $\mathrm{I} / \mathrm{R}$ region when compared with the remote region. Although not in the presentation, gene expression of collagen $1 \mathrm{~A} 1$ by quantitative PCR was increased, which further suggests increased acute activation of the TGF- $\beta$ profibrotic pathway within the I/R region that was not measured within the remote region, as demonstrated by no change in collagen $1 \mathrm{~A} 1$ gene expression and a small increase in $\mathrm{pSmad} 2$ protein abundance when compared with the referent control.

Dr Fedak. Can you speculate what the triggers could be here? Could wall stress be the key trigger, and if so, can you think of anything we can do from a surgical point of view early after reperfusion?

Dr Eckhouse. Wall stress has been demonstrated to be an important mechanism in activating MT1-MMP. We have seen this in a recent murine model of pressure overload hypertrophy from our laboratory published by Dr Zile and in in vitro aortic wall stress studies.

The alteration in stress-strain patterns due to an acute I/R event is causing an increase in MT1-MMP activation. Therefore, decreasing wall stress due to I/R remains important.

For a future surgical technique, it will be important to improve stress-strain patterns. Although this may be more relevant to a chronic infarction, improving the thickness of the affected myocardium within the I/R injury region by injections of polymers or other method is currently under investigation. However, there is a lot of area for creativity.

Dr Fedak. Thank you.

Dr Joseph D. Schmoker (Burlington, Vt). To follow up on Paul's question about regional issues, there is a mechanism for uncoupling of TGF- $\beta$ via mechanical transduction through the integrin network, I believe. I was wondering if you came across that mechanism and if that could serve as an explanation for why you are seeing this only in the region of I/R?

Dr Eckhouse. I haven't come across that mechanism specifically within this study, but one of my predecessors in the laboratory, Dr Ruddy, looked at the TGF- $\beta$ pathway within in vitro studies of aortic wall stress. We are currently investigating increased TGF- $\beta$ activation secondary to increased aortic wall stress in models of aortic aneurysms. However, I haven't looked at that within the I/R myocardial model, but that is definitely an area to look at.

Dr Schmoker. My other question relates to miR-133a, which has been used as a biomarker in clinical trials. Could it be that the interstitial levels you are measuring are simply secondary to cell injury or death secondary to reperfusion? Have you looked at that? In other words, do you have histology on your I/R region?

Dr Eckhouse. I don't have histology data to present. We did cell culture studies using primary porcine fibroblasts undergoing simulated in vitro $I / R$, and what we found when we measured miR$133 \mathrm{a}$ within the conditioned media is consistent with our in vivo evidence. When it comes to cell death, previous studies using that same I/R model did not show increased cardiomyocyte death, and we didn't have increased fibroblast cell death with our simulated hypoxia reoxygenation model.

Concurrently, with potential cell death within the I/R region, I would have expected miR-133a extracellularly to increase more with apoptosis and cell death and spillage of the intracellular miR-133a into the interstitial space. However, with I/R within that $\mathrm{I} / \mathrm{R}$ region, we actually see a decrease during the ischemic time of miR-133a.

Dr Schmoker. Right, but I think it is in the reperfusion episode where you are really going to get the cell injury or death.

One last point. Cardiac myocytes are enriched with miR-133a, but I don't know the relative abundance of that miR-133a in fibroblasts. So I am wondering why you didn't use cardiomyocytes in your cell culture.

Dr Eckhouse. That is a study we are currently doing. We haven't completed that study. We have been able to show a correlation between MT1-MMP levels and miR-133a in myocardial fibroblasts. So we are able to demonstrate that miR-133a is within other cells besides the cardiomyocytes, but we are specifically looking at the cardiomyocytes now. 
Dr Stephen McKellar (Rochester, Minn). Elegant study and model. Good presentation. You presented your I/R model here, but have you looked at this or similar phenomena in an infarction model with sampling in the infarct, border zones, and then distantly? This is an elegant way of studying that region. Is that something you could at least speculate on what you might find in that model?

Dr Eckhouse. A previous study evaluated MT1-MMP activity within an infarction model with a subsequent I/R event 2 weeks after the infarction. MT1-MMP activity increased with infarction and then subsequently increased even more after a subsequent $\mathrm{I} / \mathrm{R}$ event 2 weeks later. However, in regard to miR-133a, we haven't looked at the long-term effects of I/R on miR-133a levels, but it is definitely something we are interested in.

Dr Thomas K. Waddell (Toronto, Ontario, Canada). My question is along the lines of Dr Schmoker's question about the release of miR-133. You mentioned that the exportation was identified as a mechanism of regulation, but on the 2 slides you showed, it was clear that the Y axis was different. So when you measured by PCR the levels of the miR-133 in the interstitium versus the total, what was the scale of that difference? I would put it to you that if the total is a million, then what you are measuring in the interstitium is 10. It probably doesn't reflect regulation. What I would like you to think about is perhaps it is a mechanism of communication - the exportation of miR-133 allows that to be diffused outward. If that is the case, you might actually see increasing penumbra of decreasing miR-133 levels. So you may want to look at your remote area a little bit as proximal and distant remote.

Dr Eckhouse. We didn't look at proximal and distant remote regions of the myocardium. That is an interesting point and definitely a suggestion we will take to the laboratory. Our data with our miR exportation seem to fit nicely with our acute TGF- $\beta$ activation. In the remote region, we saw a decrease in the interstitial miR-133a levels, and it remained decreased with reperfusion, which in comparison with total myocardial pools leads us to believe that miR-133a remains elevated intracellularly. Thus, miR133a can inhibit or attenuate the TGF- $\beta$ profibrotic pathway within the remote region. Within the I/R region, the extracellular increase in miR-133a may be associated with a intracellular decrease of miR-133a, which may then allow activation of the TGF- $\beta$ profibrotic signaling pathways and promote fibrosis over time. 


\section{SUPPLEMENTAL METHODS}

\section{Model of Ischemia-Reperfusion}

Yorkshire pigs ( $\mathrm{n}=12,30-35 \mathrm{~kg}$; Hambone Farms, Orangeburg, SC) were maintained on anesthesia using morphine sulfate $(3 \mathrm{mg} / \mathrm{kg} / \mathrm{h}$ intravenously; Elkins-Sinn, Cherry Hill, $\mathrm{NJ})$ and isoflurane $\left(2 \%, 3 \mathrm{~L} / \mathrm{min} \mathrm{O}_{2}\right.$; Baxter Healthcare Corp, Deerfield, Ill), and mechanical ventilation was maintained to achieve stable arterial blood gases ( $\mathrm{pH}$ 7.35-7.45, $\mathrm{PO}_{2} \sim 300$ torr, $\mathrm{PCO}_{2} \sim 45$ torr). An arterial line was placed in the right carotid artery for continuous blood pressure monitoring, and a previously calibrated microtipped transducer catheter (7.5F; Millar Instruments Inc, Houston, Tex) was placed into the left ventricle through the left carotid artery. After a sternotomy, loosened snares were placed around the first 2 branches of the circumflex coronary artery, OM1 and OM2, which was defined as the $\mathrm{I} / \mathrm{R}$ region. A pair of sonomicrometry crystals ( $2 \mathrm{~mm}$; Sonometrics, London, Canada) was placed in this targeted I/R region, as well as another pair of sonomicrometry crystals positioned in the anterior apical left ventricle, which was defined as the remote region. A pair of microdialysis probes $(20 \mathrm{kDA}$, outer diameter of probe shaft $0.77 \mathrm{~mm}$; CMA/Microdialysis, North Chelmsford, Mass) was placed in parallel between the sonomicrometry crystals within the I/R and remote regions, respectively. A vessel loop was placed around the inferior vena cava for transient caval occlusions. All animals were treated and cared for in accordance with the National Institutes of Health Guide for the Care and Use of Laboratory Animals (1996).

After instrumentation and a 30-minute equilibration period, steady-state measurements were digitized for analysis (PONEMAH; Data Sciences, St Paul, Minn), which included heart rate, mean arterial pressure, $\mathrm{LV}$ peak systolic and end-diastolic pressures, and regional fractional segmental shortening. This was followed by simultaneous pressure dimension measurements that were recorded with transient caval occlusions to calculate regional LV preload rPRSW. ${ }^{\text {E1 }}$ After steady-state measurements, the snares were tightened for 90 minutes (ischemia) and then released for 120 minutes (reperfusion). LV function was measured at 30-minute intervals throughout I/R during the entire data-collection period. Microdialysis infusion and collection were performed as described in a subsequent section. After the end of the I/R protocol, the LV free wall was removed and quickly divided into the $\mathrm{I} / \mathrm{R}$ and remote regions. A portion of the myocardium from each region was flash-frozen in a dry ice/ethanol slurry for subsequent biochemical analysis. For the purposes of comparison, non-I/R-exposed LV myocardium from referent control pigs $(n=5)$ was harvested in an identical manner.

\section{Microdialysis and Fluorogenic Substrate Measurements}

Parallel microdialysis probes $(20 \mathrm{kDA}$, OD of probe shaft $0.77 \mathrm{~mm}$; CMA/Microdialysis) were placed within the $\mathrm{I} / \mathrm{R}$ and the remote regions, and infused ( $3 \mu \mathrm{L} / \mathrm{min})$ with MT1-
MMP or LTBP-1-quenched fluorogenic peptide substrates. The microdialysis system and MT1-MMP-specific fluorogenic substrate $[60 \mu \mathrm{mol} / \mathrm{L}$, MCA-Pro-Leu-Ala-Cys(pOMeBz)-Trp-Ala-Arg(Dpa)-NH2; Calbiochem, La Jolla, Calif; cat. no. 444258] has been described and validated. ${ }^{\text {E2-E4 }}$ To create a fluorogenic construct of LTBP-1 proteolysis mediated by MT1-MMP, the full-length sequence of LTBP-1 was first examined to identify potential MT1MMP-specific binding/cleavage sites. ${ }^{\text {E2-E4 }}$ From these in silico studies, a specific sequence identified to contain an MT1-MMP cleavage site was used to synthesize a quenched fluorogenic peptide substrate (Dabcyl-Ala-Gly-Gly-GluAsn-Try-Lys-Asp-EDANS; National Center for Biotechnology Information; AA30290.1). ${ }^{\text {E2-E4 }}$ Past in vitro studies have demonstrated that this LTBP-1 substrate yielded a linear fluorescent signal with increasing concentrations of recombinant MT1-MMP, which was extinguished with MT1-MMP neutralizing antibody, MT1-MMP selective inhibitor, or a global MMP inhibitor. ${ }^{\mathrm{E} 4}$ In the present study, $60 \mu \mathrm{mol} / \mathrm{L}$ of LTBP-1 substrate was infused into the myocardial interstitium, and peptide hydrolysis was measured using the microdialysis system. All microdialysis tubing and dialysate collected were protected from ambient light. Fluorescence in the dialysate from the hydrolyzed peptides was measured at excitation/emission wavelength of $328 \mathrm{~nm} /$ $400 \mathrm{~nm}$ for the MT1-MMP substrate and $340 \mathrm{~nm} / 405 \mathrm{~nm}$ for the LTBP-1 substrate (FLUOstar Galaxy fluorescent microplate reader; BMG LABTECH Inc, Cary, NC).

\section{Immunoblotting}

For determination of $\mathrm{pSmad} 2$ and $\mathrm{Smad} 2$ within the myocardium, tissue samples were sequentially extracted as previously described. ${ }^{\text {E1 }}$ Briefly, myocardial samples were homogenized in extraction/homogenization buffer (buffer volume used is $1: 6 \mathrm{w} / \mathrm{v}$; containing $10 \mathrm{mmol} / \mathrm{L}$ cacodylic acid $\mathrm{pH} 5.0,0.15 \mathrm{~mol} / \mathrm{L} \mathrm{NaCl}, 20 \mathrm{mmol} / \mathrm{L} \mathrm{ZnCl}, 1.5 \mathrm{mmol} / \mathrm{L}$ $\mathrm{NaN}_{3}, 0.01 \%$ Triton $\mathrm{X}-100$ [v/v], a protease inhibitory cocktail [cat no. P8340; Sigma, St Louis, Mo]) and centrifuged ( $800 \mathrm{~g}, 10$ minutes, $4^{\circ} \mathrm{C}$ ). The supernatant was removed, and protein concentrations were determined by using a bicinchoninic acid protein assay (product 23225; Thermo Scientific, Rockford, Ill). For these studies, immunoblotting was first performed for $\mathrm{pSmad} 2$, and the membranes were stripped and reprobed for total Smad2 (cat no. 3101, 5339, respectively, 1:1000; Cell Signaling, Danvers, Mass). The immunoreactive signals were analyzed using densitometric methods (Gel Pro Analyzer; Media Cybernetics Inc, Rockville, Md) to obtain 2-dimensional integrated optical density values.

\section{MicroRNA Isolation and Quantification}

The extracted myocardial RNA $(1 \mu \mathrm{g})$ was reverse transcribed (iScript cDNA Synthesis Kit; Bio-Rad, Hercules, Calif) and amplified with gene-specific primer/probe sets (TaqMan Universal PCR Master Mix, catalog no. 
4364321, Applied Biosystems, Foster City, Calif) using real-time PCR (CFX96 real-time PCR detection system; Bio-Rad). The specific primer/probe sets were synthesized for porcine LTBP-1 (Integrated DNA Technologies [Coralville, Iowa], custom sequence: forward 5'-AGGCCG TA CTGGCTCTTTACAACA- $3^{\prime}$ reverse 5'-AGCCAGAGGC GGACTACTACGC CAA- $3^{\prime}$ probe $5^{\prime}$-/56FAM/TTGGTTG CCGCTTTCCACCATTAG/3BHQ-1/-3') and TGF- $\beta$ R 1 (Integrated DNA Technologies, custom sequence: forward 5'-AAAGCTACATAACCTAC GGCCC-3' reverse 5'-ACT GAATCCTTGCTCGTCTG-3' probe $5^{\prime} / 56$-FAM/TGC CG TATT/Zen/TCCAACACTCTGGGT/31ABkFQ/ $/ 3^{\prime}$ ), and those for MT1-MMP, MMP-9, type I collagen, and 18S rRNA were obtained commercially (Catalog no. Ss03394431_m1, Ss03392098_m1, Ss03373340_m1, and Hs99999901_s1, respectively, Applied Biosystems). Negative controls were run to verify the absence of genomic DNA contamination (reverse transcription control) and the absence of overall DNA contamination in the PCR system and working environment (template control).

\section{Bioinformatics Analysis of MicroRNA-133a}

In silico mapping of the $3^{\prime}$-UTR of the human MT1MMP gene (TargeScan Human 5.1, www.targetscan.org) identified a high-probability target for miR-133a context score $\left.-0.17, \mathrm{P}_{\mathrm{Ct}} 0.34\right) .{ }^{\mathrm{E}-\mathrm{E} 8}$ Of note, the 8 -mer seed sequence was perfectly replicated in the $3^{\prime}$-UTR of the porcine MT1-MMP gene. Moreover, when the human and porcine 3'-UTRs of MT1-MMP are aligned (ClustalW2; http://www.ebi.ac.uk/Tools/msa/clustalw2/), the miR-133 target nucleotide sequence matches with identity at 25 of 31 base pairs, suggesting that porcine MT1-MMPs also possess a high-fidelity target site for miR-133a. In similar fashion, miR-133a putatively targets several other genes that play an important role in the profibrotic response, including MMP-9, LTBP-1, TGF- $\beta$ R1, and type I collagen. ${ }^{\mathrm{E}, \mathrm{E} 9, \mathrm{E} 10}$

\section{MicroRNA Isolation and Quantification}

The microdialysate samples $(100 \mu \mathrm{L})$ underwent miR isolation from both the $\mathrm{I} / \mathrm{R}$ and remote regions at steady state, 90 minutes ischemia, and 20 minutes reperfusion (miRVana PARIS miR Isolation Kit, Catalog no. AM1556, Applied Biosystems). The conditioned media samples $(100 \mu \mathrm{L})$ collected after 120 minutes of normoxia, 90 minutes of hypoxia, and 120 minutes of reoxygenation also underwent miR isolation (miRVana PARIS miR Isolation Kit, catalog no. AM1556, Applied Biosystems). A custom-made exogenous Caenorhabditis elegans miR-39 sequence (10 ng; cel-miR-39; Integrated DNA Technologies) was added to each sample of microdialysate and conditioned medium to measure extraction efficiency.

The myocardial samples $(30 \mathrm{mg})$ were homogenized (TissueLyser; Qiagen, Valencia, Calif), and the total RNA was extracted (RNeasy Fibrous Tissue Mini Kit; Catalog no. 74704; Qiagen). Total RNA quality and quantity were then assessed (Experion Automated Electrophoresis System and StdSens RNA Analysis Kit, catalog no. 7007103 , Bio-Rad), and aliquots were frozen at $-80^{\circ} \mathrm{C}$.

Isolated RNA from the microdialysate, conditioned media, and myocardial homogenate was reverse transcribed (TaqMan MicroRNA Reverse Transcription Kit; Applied Biosystems) and preamplified (TaqMan PreAmp Master Mix; Applied Biosystems). Specific miR expression (hsa-miR29a Assay ID 002112, hsa-miR-133a-1 Assay ID 002246; TaqMan MicroRNA RT Kit 4366579; Applied Biosystems) was analyzed with real-time PCR (CFX96 real-time PCR detection system; Bio-Rad) using a 2-step procedure: Initial denaturation for 10 minutes at $95^{\circ} \mathrm{C}$ was followed by 40 cycles of 15 seconds at $95^{\circ} \mathrm{C}$ and 60 seconds at $60^{\circ} \mathrm{C}$.

\section{Simulated Ischemia-Reperfusion in Porcine Left Ventricular Fibroblasts}

In light of the fact that past in vitro studies have identified potential trafficking of specific miRs, ${ }^{\text {E11 }}$ the present study examined whether and to what degree indices of miR trafficking could be identified with $\mathrm{I} / \mathrm{R}$ by using a porcine $\mathrm{LV}$ fibroblast system of hypoxia and reoxygenation. Isolation of porcine LV fibroblasts ( $\mathrm{n}=3$ independent cell lines from 3 separate control pigs) was performed as previously described. ${ }^{\mathrm{E} 12} \mathrm{Fi}-$ broblasts were grown to confluence in complete fibroblast growth medium (FGM) (catalog no. C23010; Promocell, Heidelberg, Germany) containing $20 \%$ fetal bovine serum (catalog no. 10082-147; Invitrogen, Carlsbad, Calif), fibroblast growth supplement (Promocell, catalog no. C39325), amphotericin B (2.5 ng/mL, catalog no. C42040, Promocell), and gentamicin $(50 \mu \mathrm{g} / \mathrm{mL}$, catalog no. C42060, Promocell), and incubated under standard culture conditions $\left(37^{\circ} \mathrm{C}, 5 \%\right.$ $\mathrm{CO}_{2}, 21 \% \mathrm{O}_{2}$ ). For these studies, each independent cell line was assayed in triplicate. Cells from each line were plated onto three $60-\mathrm{mm}$ dishes $(300,000$ cells/dish) and incubated overnight in complete medium without antibiotics or antifungals. The following day, the medium was aspirated and the cells were washed ( $2 \mathrm{~mL}$, fresh medium). The fibroblasts were then subjected to 120 minutes of normoxia in FGM $\left(2 \mathrm{~mL}, 37^{\circ} \mathrm{C}, 5 \% \mathrm{CO}_{2}, 21 \% \mathrm{O}_{2}\right)$. At the end of the normoxia period, the medium was collected and centrifuged (450g for 4 minutes) to remove any cellular material. The dishes were then incubated in FGM that had been depleted of all oxygen content (hypoxia medium, $2 \mathrm{~mL}$ ). To ensure adequate oxygen depletion of the hypoxia medium, complete FGM was infused with $95 \%$ nitrogen, $5 \% \mathrm{CO}_{2}$ for 30 minutes (at $37^{\circ} \mathrm{C}$ ) before the addition to the fibroblast cultures. The dishes were then placed into microincubators (Radnoti Glass Technology, Monrovia, Calif) with circulating 95\% nitrogen, $5 \% \mathrm{CO}_{2}$ for 90 minutes (at $37^{\circ} \mathrm{C}$ ). The media were again collected and centrifuged to remove any cellular material as before ( $450 g$ for 4 minutes). Next, the same fibroblast cultures were subjected to reoxygenation by the readdition of 
normoxic FGM $(2 \mathrm{~mL})$ for 120 minutes $\left(37^{\circ} \mathrm{C}, 5 \% \mathrm{CO}_{2}\right.$, $21 \% \mathrm{O}_{2}$ ). After reoxygenation, the conditioned media were once again collected. All of the conditioned media samples were stored at $-80^{\circ} \mathrm{C}$ until analysis.

\section{In Vitro Membrane Type 1 Matrix Metalloproteinase Protein Modulation}

To examine the role of miR-133a in regulating protein levels of MT1-MMP, tools for permanent overexpression and inhibition were used. Accordingly, human LV myocardial fibroblasts $\left(2 \times 10^{5}\right.$ cells $)(n=3)$ were grown to $70 \%$ confluence in sterile T-25 culture flasks (BD Falcon, Le Pont De Claix, France). After 24 hours, fibroblasts were transduced with 1 of 2 lentiviral vectors allowing for the delivery of an miR precursor to LV fibroblasts in culture with a multiplicity of infection of 10 in a $1 \times$ concentration of a transduction efficiency reagent, Transdux (System Biosciences) in fibroblast basal media with added supplement mix and $10 \%$ fetal bovine serum for 3 days. Overexpression of miR-133a was accomplished with the use of the pMIRNA1has-miR-133a-1 lentivector (System Biosciences). For knockdown of miR-133a levels, the anti-miR-133a lentiviral vector construct (pmiRZip-has-miR-133a-1; System Biosciences) will result in the production of singlestranded anti-miRs that competitively bind to endogenous miR-133a targets, inhibiting interaction with mRNA. Five days after transduction, the fibroblasts were collected and analyzed by immunoblotting for MT1-MMP (AB8221; Millipore, Billerica, Mass). The immunoreactive signals were analyzed using densitometric methods (Gel Pro Analyzer, Media Cybernetics Inc) to obtain 2-dimensional integrated optical density values.

\section{Computations and Data Analysis}

Statistical analyses were performed using STATA statistical software (StataCorp, College Station, Tex). LV regional function and hemodynamics were compared between groups by ANOVA (prcomp module, STATA). Fluorescence values corresponding to the interstitial MT1MMP activity and MT1-MMP-mediated LTBP-1 substrate hydrolysis were evaluated by ANOVA and expressed as a percent change from steady-state values (steady state set to zero). The integrated optical density values for $\mathrm{pSmad} 2$ and Smad2 were then computed as a percent of control values (control values set to 100), and comparisons were performed by using a 1 -sample $t$ test. For the myocardial miR levels and mRNA levels of MT1-MMP, MMP-9, LTBP-1, TGF- $\beta$ R1, and COL1A1, Ct values were normalized to $18 \mathrm{~S} \mathrm{Ct}$ values (miR-Ct-18S-Ct $=\Delta \mathrm{Ct}$ ) and then converted to expression levels (miR expression level $\left.=2^{(-\Delta \mathrm{Ct})}\right) .{ }^{\mathrm{E} 13}$ Myocardial miR expression levels also were compared with control values (fold change miR expression $\left.=2^{-(\Delta \mathrm{Ct} \text {-control } \Delta \mathrm{Ct})}\right) \cdot{ }^{\mathrm{E} 13} \mathrm{~A} t$ test was performed comparing fold change in expression with control (set to
1.0). For interstitial miR levels, the $\mathrm{Ct}$ values were normalized to $C$ elegans miR-39 Ct values (miR-Ct - miR$39-\mathrm{Ct}=\Delta \mathrm{Ct}$ ) and converted to expression levels (miR expression level $\left.=2^{-(\Delta \mathrm{Ct})}\right)$, as previously described. ${ }^{\mathrm{E} 13}$ Interstitial miR expression levels were first compared between groups by ANOVA and then expressed as a percent change from steady state. A $t$ test was performed on the percent change in interstitial miR expression (steady state set to zero percent change). A $t$ test was performed on the percent change of referent control for MT1-MMP protein abundance (steady state set to $100 \%$ change). For conditioned medium miR levels, the $\mathrm{Ct}$ values were normalized to C elegans miR-39 Ct values ( $\mathrm{miR} \mathrm{Ct}-\mathrm{miR}-39 \mathrm{Ct}=\Delta \mathrm{Ct})$ and then converted to expression levels (miR expression level $\left.=2^{-(\Delta \mathrm{Ct})}\right)$, as previously described. ${ }^{\mathrm{E} 13}$ A 1-way $t$ test was performed on the percent change in conditioned medium miR expression (steady state set to $100 \%$ change). Post hoc mean separation after each ANOVA was performed using Bonferroni-adjusted pairwise comparisons. Results are presented as the mean \pm standard error of the mean.

\section{E-References}

E1.Deschamps AM, Yarbrough WM, Squires CE, Allen RA, McClister DM, Dowdy KB, et al. Trafficking of the membrane type-1 matrix metalloproteinase in ischemia and reperfusion: relation to interstitial membrane type-1 matrix metalloproteinase activity. Circulation. 2005;111:1166-74.

E2. Karsdal MA, Larsen L, Engsig MT, Lou H, Ferreras M, Lochter A, et al. Matrix metalloproteinase-dependent activation of latent transforming growth factorbeta controls the conversion of osteoblasts into osteocytes by blocking osteoblast apoptosis. J Biol Chem. 2002;277:44061-7.

E3.Rodriguez D, Morrison CJ, Overall CM. Matrix metalloproteinases: what do they not do? New substrates and biological roles identified by murine models and proteomics. Biochim Biophys Acta. 2010;1803:39-54.

E4. Spinale FG, Mukherjee R, Zavadzkas JA, Koval CN, Bouges S, Stroud RE, et al. Cardiac restricted overexpression of membrane type-1 matrix metalloproteinase causes adverse myocardial remodeling following myocardial infarction. $J$ Biol Chem. 2010;285:30316-27.

E5.Friedman RC, Farh KK, Burge CB, Bartel DP. Most mammalian mRNAs are conserved targets of microRNAs. Genome Res. 2009;19:92-105.

E6.Grimson A, Farh KK, Johnston WK, Garrett-Engele P, Lim LP, Bartel DP. MicroRNA targeting specificity in mammals: determinants beyond seed pairing. Mol Cell. 2007;27:91-105.

E7.Lewis BP, Burge CB, Bartel DP. Conserved seed pairing, often flanked by adenosines, indicates that thousands of human genes are microRNA targets. Cell. 2005; 120:15-20.

E8. Rehmsmeier M, Steffen P, Hochsmann M, Giegerich R. Fast and effective prediction of microRNA/target duplexes. RNA. 2004;10:1507-17.

E9.Duisters RF, Tijsen AJ, Schroen B, Leenders JJ, Lentink V, van der Made I, et al. miR-133 and miR-30 regulate connective tissue growth factor: implications for a role of microRNAs in myocardial matrix remodeling. Circ Res. 2009;104: 170-8, 6p following 8 .

E10. Matkovich SJ, Wang W, Tu Y, Eschenbacher WH, Dorn LE, Condorelli G, et al. MicroRNA-133a protects against myocardial fibrosis and modulates electrical repolarization without affecting hypertrophy in pressure-overloaded adult hearts. Circ Res. 2010;106:166-75.

E11.Wang K, Zhang S, Weber J, Baxter D, Galas DJ. Export of microRNAs and microRNA-protective protein by mammalian cells. Nucleic Acids Res. 2010; 38:7248-59.

E12. Flack EC, Lindsey ML, Squires CE, Kaplan BS, Stroud RE, Clark LL, et al. Alterations in cultured myocardial fibroblast function following the development of left ventricular failure. J Mol Cell Cardiol. 2006;40:474-83.

E13.Livak KJ, Schmittgen TD. Analysis of relative gene expression data using realtime quantitative PCR and the 2(-Delta Delta C(T)) Method. Methods. 2001;25: 402-8. 
TABLE E1. Left ventricular function and hemodynamics during the ischemia-reperfusion protocol

\begin{tabular}{|c|c|c|c|c|c|}
\hline & \multirow[b]{2}{*}{ Steady state } & \multicolumn{2}{|c|}{ Ischemia (min) } & \multicolumn{2}{|c|}{ Reperfusion (min) } \\
\hline & & 30 & 90 & 30 & 120 \\
\hline Heart rate (beats/min) & $84 \pm 5$ & $86 \pm 5$ & $88 \pm 4$ & $115 \pm 7^{*}, \dagger$ & $115 \pm 7^{*}, \dagger$ \\
\hline Mean arterial pressure $(\mathrm{mm} \mathrm{Hg})$ & $82 \pm 2$ & $80 \pm 3$ & $82 \pm 3$ & $78 \pm 3$ & $80 \pm 4$ \\
\hline LV peak systolic pressure $(\mathrm{mm} \mathrm{Hg})$ & $95.6 \pm 2.0$ & $92.7 \pm 3.5$ & $96.2 \pm 3.5$ & $89.0 \pm 3.8$ & $96.1 \pm 4.2$ \\
\hline LV end-diastolic pressure $(\mathrm{mm} \mathrm{Hg})$ & $6.9 \pm 0.7$ & $7.6 \pm 1.1$ & $8.1 \pm 1.0$ & $7.3 \pm 0.9$ & $6.8 \pm 0.9$ \\
\hline \multicolumn{6}{|l|}{ Segmental shortening $(\%)$} \\
\hline $\mathrm{I} / \mathrm{R}$ region & $15.21 \pm 2.02$ & $2.79 \pm 2.21 *$ & $2.94 \pm 1.75^{*}$ & $0.81 \pm 1.72 *$ & $3.11 \pm 2.32 *$ \\
\hline Remote region & $13.38 \pm 1.30$ & $13.08 \pm 1.54$ & $12.66 \pm 1.39$ & $8.91 \pm 1.13$ & $9.81 \pm 1.15$ \\
\hline
\end{tabular}

Values represent mean \pm standard error of the mean; $\mathrm{n}=12$. $L V$, Left ventricular; $I / R$, ischemia-reperfusion. ${ }^{*} P<.05$ versus steady state. $\dagger P<.05$ versus 90 minutes ischemia. 